\title{
The Analysis of the Stress-Strain State of the System "Equipment Complex - Support - Rock Mass" in the Bottomhole Area of the Shaft
}

\author{
Alexander Pankratenko ${ }^{1, *}$, and Alexander Isaev $^{2}$ \\ ${ }^{1}$ National University of Science and Technology MISIS (Moscow Institute of Steel and Alloys), \\ Department of underground structures and mining enterprises, 119991, Leninskij Av., 4, Moskow, \\ Russia \\ ${ }^{2}$ VostokCoal Management Company, 143084, estate 100, "Residence on Rublevka" Business Center, \\ Usovo, Odinstovsky District, Moscow Region, Russia
}

\begin{abstract}
The development of new deposits enterprises requires the construction of deep and super deep vertical shafts. The duration of their construction reaches 8 - 10 years with multi-billion capital investments. To reduce the payback period of these costs, it is necessary to develop and implement effective solutions to increase the speed of sinking operations through the wide introduction of brand-new mechanized equipment complexes. In response to the sinking in the bottomhole area of the shaft a complex, the following geotechnological system is being formed: "tunneling system - support - rock mass", the regularities of which require further study. For these purposes, an analytical method for calculating the shaft support can be used in the context of consideration of a planar contact problem at various phases of the system operation. The mutual coordination of individual phases in accordance with the classical concepts of the underground structures mechanics is possible with the help of a correction factor to the magnitude of horizontal stresses in the rock mass. In this paper we developed the algorithm which determines this coefficient, taking into account the influence of the main technological factors: the jack system pressure of the complex and the speed of sinking.
\end{abstract}

\section{Introduction}

The development of new deposits and the reconstruction of existing mining enterprises requires the construction of deep and super deep vertical shafts. The duration of their construction reaches $8-10$ years with multi-billion capital investments. To reduce the payback period of these costs, it is necessary to develop and implement effective solutions to increase the speed of sinking operations through the wide introduction of brand-new mechanized equipment complexes.

Over the past 35 years, long-length shafts in Russia and the CIS countries have been built using drill and blast tunneling method. A major drawback of this technology is the

* Corresponding author: mixail-stepan@mail.ru 
lack of the possibility of combining the most laborious tunneling processes at the shaft foot: drilling and blasting and shaft mucking. Owe to this, the average rate of shaft construction did not exceed $30-50 \mathrm{~m} /$ month, which is $2-3$ times less than in case of the application of drifting operation and slope sinking.

A promising direction to solve this problem is the widespread introduction of brand new mechanized equipment complexes of domestic (SPKV, ASP) and foreign (Herrenknecht $\mathrm{AG}$, etc.) production during the deep shaft sinking. However, their wider application is hampered by a number of undeveloped issues related to the validation of a rational area of application and parameters of an effective technology for sinking with mechanized equipment complexes.

The last comprehensive scientific research devoted to mechanized sinking of shafts was carried out in the last century by the leading Russian scientists and specialists of the "Donetskshahtoprokhodka" and Research and Development Establishment "podzemmash" (Turkyan R.A., Stoev I.S., Novik E.B., Levit V.V. etc.). Their result was the successful introduction of the SK-1u complex while driving the cage type shaft No. 3 named after M.I. Kalinin. The maximum rate of sinking was $160 \mathrm{~m} /$ month. with the productivity of the drifters $-15.02 \mathrm{~m}^{3} /$ person-shift.

The achieved results were not further developed due to the difficult economic situation in the country. The questions connected with the determination of the optimal parameters of mechanized sinking and the influence of the operation speed on the interaction features of the support and rock mass in the shaft remained unexplored.

In the works of Amusin B.Z., Baklashov I.V., Bolikov E.V., Borshchevsky S.V., Bulychev N.S., Kartoziya B.A., Levit V.V., Palankoev I.M., Pankratenko A.N., Pleshko M.S., Protoseni A.G., Shuplik M.N., Syrkin P.S., Kharisov T.F., Yagodkin F.I. and others, features of the interaction of the support and rock mass in the bottomhole working area are considered taking into account the sinking technology, the influence of adjacent and adjacent workings, special operation methods and other factors. The obtained results have been successfully adapted to the drilling and blasting technology of shaft sinking by combined and parallel schemes [1-13]. At the same time, high rate sinking of shafts by mechanized equipment complexes is characterized by a different sequence of opening the crosscut end and the time periods for the entry of permanent and temporary support into work, the absence of a negative influence on the structures in the shaft and the surrounding rock mass of blasting operations, additional loads on the support from the tunnel system and other features. In the bottomhole area of the shaft, a complex geotechnological system is being developed, the "tunneling system - support - rock mass" (hereinafter - system), the regularities of which require further study.

\section{Materials and Methods}

For these purposes, the analytical method of calculating the trunks was widely used. It is based on the investigation of the complex interaction of the support and the surrounding rock mass within the framework of a planar problem, as a result of which a static equilibrium with certain values of stresses and deformations is formed. Their values essentially depend on the compliance of the support, its pit bottom standoff term, the parameters of the operation technology and a number of other factors [7-9].

When considering the system in the bottomhole area of the shaft, constructed on a parallel technological scheme, it is necessary to take into account:

1. The amount of the drifting face advancing per cycle.

2. The impact of the mechanized equipment complex on the rock mass and the shaft support.

3. The standoff of temporary (if any) and permanent support from the pit bottom. 
4. Speed of permanent support come into the operation.

A generalized scheme of interaction of the system "tunneling complex - support - rock mass" in the bottomhole area of the shaft is shown in Fig. 1.

In phase 1, the development of the shaft foot is carried out by a mechanized equipment complex. The wall rock in this section, with its sufficient stability, is not fixed and can be easily deformed.

In phase 2, the jack system of the complex ensures its stability and transfers pressure $P_{d}$ to the rock walls, which limits further unloading of the rock mass. Thus, it performs the function of active temporary support for a short period of time.

In phase 3, the shaft support is built and put into operation with the perception of $\mathrm{P}_{\mathrm{r}}$ pressure. On application of the prefabricated support, the strength and deformation characteristics of the rings 3-6 can be assumed to be the same. In the case of fastening the shaft with monolithic concrete, the support parameters are determined by the actual age of the concrete, the rate of its hardening, and increase from 3rd to 6th ring.

a

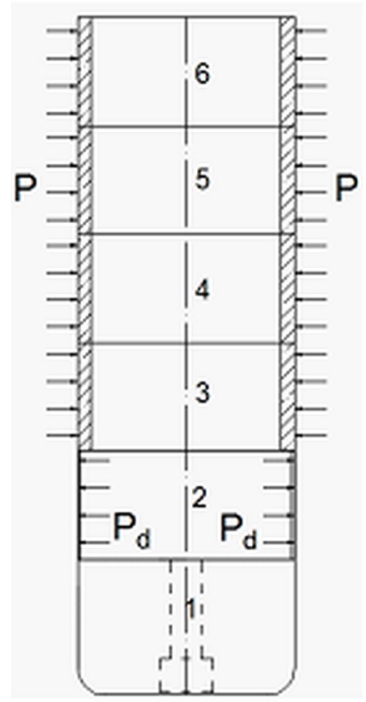

b

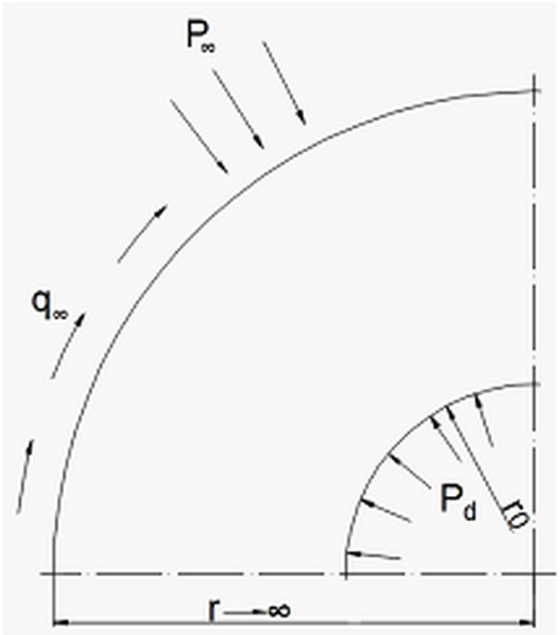

Fig. 1. Interaction model of the system «mechanized equipment complex - support - rock mass» in the bottomhole area of the shaft: $a$ - layer; $b$ - section (phase 2).

The extended part of the trunk mentioned above is a stabilized rock mass, fixed with support with design parameters outside the zone of the pit bottom impact and the tunneling system.

The mutual coordination of these schemes in accordance with the classical concepts of the mechanics of underground structures is possible with the help of a correction factor to the magnitude of horizontal stresses in the rock mass $\alpha^{*}$. Let us consider an algorithm for its determination for the problem being solved.

\section{Main part}

The initial data for calculating the initial stresses in an non-uniform field are:

$N_{1}$ anf $N_{2}$ - The calculated principal stresses of the tight rock performing in the horizontal plane; 
$E, E_{1}, G_{1}, G_{2}, \mu, \mu_{1}$ - respectively, deformation modulus, shear modulus and the Poisson ratio of rocks and support;

$\gamma$ - bulk weight of rocks;

$\lambda$ - coefficient of lateral earth pressure;

$r_{0}, r_{1}$ - outer and inner radii of the cross-section of the support;

$H$-depth of the gage section of the shaft.

The expression for determining the coefficient $\alpha^{*}$ in the framework of the problem under consideration is conveniently presented in the form

$$
a^{*}=1-\frac{u_{t}}{u_{\infty}}
$$

where $u_{t}$ is the displacement of the unfastened working contour for a period of time $t$ elapsed from the development of the bottom hole to the entry of the support into the work in the cross-section of the shaft under consideration;

$u_{\infty}$ - full shear of the unfastened working.

The shear $u_{\infty}$ of an unfastened working when considering the elastic problem can be determined by the well-known formula [9]

$$
u_{t}=\frac{r_{0}}{2 G} \lambda \gamma H
$$

To determine the shear $u_{t}$ based on the analysis of the first and second phases of the interaction of the system, we obtain the expression

$$
u_{l}=\frac{r_{0}}{2 G}\left(\left(1-\alpha_{1}\right) \lambda \gamma H+\left(\alpha_{1}-\alpha_{2}\right)\left(\lambda \gamma H-P_{d}\right)\right)
$$

where $\alpha_{\mathrm{i}}$ - correction factor, determined depending on the sinking rate

$$
\alpha_{i}=\exp \left(-0,3 \frac{V t_{i}}{r_{0}}\right)
$$

where $V$ - rate of drifting face advancing per cycle, $\mathrm{m} /$ day;

$t_{i}$ - considered period of time, day.

When considering the system using a rigid prefabricated support using the procedure, the load on the support (stresses on the contact of the support with the rocks) are determined by the formulas:

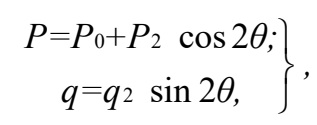

where $P$ - radial stresses (loads);

$q$ - tangential stresses;

$\theta$ - polar angle, measured in the horizontal plane from the direction of the greatest stresses $N_{1}$; 


$$
\left.\begin{array}{c}
P_{0}=\alpha^{*} N_{1} \frac{1+\xi}{2}\left(1-k_{0}^{*}\right) ; \\
P_{2}=\alpha^{*} N_{1} \frac{1+\xi}{2}\left(1-k_{11}^{*}+k_{12}^{*}\right) ; \\
q_{2}=\alpha^{*} N_{1} \frac{1+\xi}{2}\left(-1-k_{21}^{*}+k_{22}^{*}\right)
\end{array}\right\}
$$

$k_{0}{ }^{*} ; k_{11}{ }^{*} ; k_{12}{ }^{*} ; k^{*}{ }_{21} ; k_{22}{ }^{*}$ - the transmission coefficients of additional (removable) stresses, determined by formulas:

$$
\begin{array}{r}
k_{0}^{*}=\frac{\chi_{1}+1}{c_{1}^{2}\left(\chi_{1}-1\right)+2+2\left(c_{1}^{2}-1\right) \frac{G_{1}}{G_{2}}} ; \\
k_{11}^{*}=\frac{1}{B^{\prime}}\left(\delta_{1} b_{3}^{\prime}-\delta_{2} b_{3}\right) \\
k_{12}^{*}=\frac{1}{B^{\prime}}\left(\delta_{2} b_{4}^{\prime}-\delta_{1} b_{4}^{\prime}\right) \\
k_{21}^{*}=\frac{1}{B^{\prime}}\left(\gamma_{1} b_{3}^{\prime}-\gamma_{2} b_{3}\right) \\
k_{22}^{*}=\frac{1}{B^{\prime}}\left(\gamma_{2} b_{4}-\gamma_{1} b_{4}^{\prime}\right)
\end{array}
$$

where

$$
\begin{gathered}
B^{\prime}=\gamma_{2} \delta_{1}-\gamma_{1} \delta_{2} ; \quad \delta_{1}=b_{2}-\chi^{\prime \prime} ; \quad \delta_{2}=b_{2}^{\prime}-\chi^{\prime \prime} ; \quad \gamma_{1}=b_{1}+\chi^{\prime \prime} ; \\
\gamma_{3}=b_{1}^{\prime}-\chi^{\prime \prime} ; \quad b_{1}=c_{1}^{4}\left(3+c_{1}^{2}\right)-D_{1} ; \quad b_{2}=c_{1}^{4}\left(3-c_{1}^{2}\right)+D_{1} ; \\
b_{3}=c_{1}^{2}\left(3 c_{1}^{2}+1\right) ; \quad b_{1}=c_{1}^{2}\left(3 c_{1}^{2}-1\right) ; \quad b_{2}=2 c_{1}^{4}+c_{1}^{2}+1+D_{1} ; \\
b_{2}^{\prime}=c_{1}^{2}+1+D_{1} ; \quad b_{3}^{\prime}=c_{1}^{2}\left(c_{1}^{2}+1\right)+2 ; \quad b_{4}^{\prime}=c_{1}^{2}\left(c_{1}^{2}+1\right) ; \\
c_{1}=\frac{R_{1}}{R_{0}} ; \quad \chi_{1}=3-4 \mu_{1} ; \quad D_{1}=\frac{\left(c_{1}^{2}-1\right)^{3}}{\chi_{1}+1} ; \chi^{\prime \prime}=\frac{E_{1} 1+\mu}{E 1+\mu} D_{1} .
\end{gathered}
$$

Further, the normal tangential stresses on the inner and outer contours of the support are determined by the formulas:

$$
\left.\begin{array}{c}
\sigma_{\theta}^{B H}=n_{p} P_{0} m_{1}-\left(P_{2} n_{1}-q_{2} n_{2}\right) \cos 2 \theta \\
\sigma_{\theta}^{\text {uap }}=n_{p} P_{0} m_{1}^{\prime \prime}+\left(P_{2} n_{1}^{\prime}-q_{2} n_{2}^{\prime}\right) \cos 2 \theta
\end{array}\right\},
$$

where 


$$
\begin{gathered}
m_{1}=\frac{2 c_{1}^{2}}{c_{1}^{2}-1} ; \quad m_{1}^{\prime}=m_{1}-1 ; \quad n_{1}=4 c_{1}^{2} \frac{\left(c_{1}^{2}+1\right)}{\left(c_{1}^{2}-1\right)^{2}} ; \\
n_{1}^{\prime}=\frac{\mathrm{c}_{1}^{4}+6 \mathrm{c}_{1}^{2}+1}{\left(\mathrm{c}_{1}^{2}-1\right)^{2}} ; \quad n_{2}=\frac{4 \mathrm{c}_{1}^{2}}{\left(\mathrm{c}_{1}^{2}\right)^{2}} ; \quad n_{2}^{\prime}=2 \frac{2 \mathrm{c}_{1}^{2}+1-c_{1}^{4}}{\left(\mathrm{c}_{1}^{2}-1\right)^{2}} ;
\end{gathered}
$$

$n_{p}$ - overloading ratio.

To evaluate the qualitative influence of the technological parameters of the system: the sinking rate $V$ and the pressure of the jacks of the complex $P_{d}$, we use the dimensionless coefficients

$$
k_{V}=\frac{V t_{i}}{r_{0}} ; k_{P}=\frac{\lambda \gamma H}{P_{d}} .
$$

Examples of the obtained dependences of the relative stresses in the $N_{\text {rel }}$ support (the ratio of the stresses, respectively, taking into account and without taking into account the influence of the system) are shown in Fig. 2.

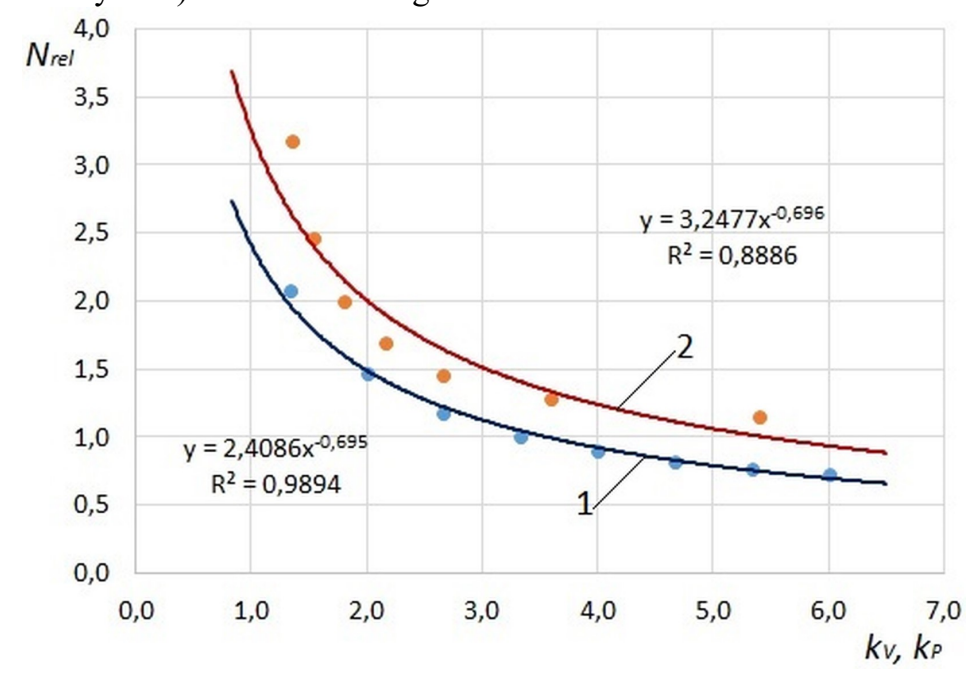

Fig. 2. Dependency graphs: $1-N_{r e l}(k v) ; 2-N_{r e l}(k P)$.

Dependencies with a satisfactory degree of reliability of approximation are described by power functions. Their analysis shows that the influence factor of the sinking rate has a favorable effect on the magnitude of stresses in the support. On the contrary, the pressure of the jacks can restrain the unloading of the rock mass and leads to an additional increase in stresses in the support.

In case of consideration of the system with the use of monolithic concrete support, it is necessary to take into account the flexibility of concrete at an early age.

For estimated calculations, the coefficient $k_{b}$, determined in accordance with [11], based on the empirical dependence:

$$
k_{B}=\left(2,26 \frac{r_{0}-r_{1}}{r_{0}}+0,623\right) \cdot \exp \left(0,4 \frac{E_{7}}{E_{28}}\right),
$$

where $t$-support thickness, m;

$E_{7}$ - modulus of concrete deformation at the age of 7 days.; 
$E_{28}-$ modulus of concrete deformation в at the project age.

\section{Conclusions}

The disadvantage of the presented technique is the inability to take into account the influence of individual phases on each other, the heterogeneity of the rock mass and the spatial geometry of the shaft, for example, on the sections of interfaces and chambers. This requires the consideration of spatial numerical models in a nonlinear formulation, which stage by stage examine the phases of interaction of the system in the bottomhole area of the shaft.

\section{References}

1. F. Yagodkin, M. Pleshko, A. Prokopov, Procedia Engineering, 206 (2017)

2. F.I. Yagodkin, A.Y. Prokopov, M.S. Pleshko, A.N. Pankratenko, IOP Conference Series: Earth and Environmental Science, 062014 (2017)

3. X. Zhang, Y. Han, S. Liu, C. Su Liaoning, Journal of Liaoning Technical University, 33, 8 (2014)

4. M. Huang, B. Wu, H. Liu, Z. Tan, China Civil Engineering Journal, 48 (2015)

5. O.S. Kaledin, Gornyj zhurnal, 4 (2014)

6. I.V. Baklashov, B. A. Kartozia, Mechanics of underground structures and structures of supports (Nedra, Moscow, 1992)

7. I. V. Baklashov, Geomechanics (Publishing house of the Moscow State Mining University, Moscow, 2004)

8. N. S. Bulychev, The mechanics of underground structures in examples and tasks (Nedra, Moscow, 1989)

9. M. S. Pleshko, M. V. Pleshko, GIAB, 7 (2012)

10. M. S. Pleshko, V. A. Kurnakov, GIAB, 4 (2011)

11. M. S. Pleshko, GIAB, 4 (2010)

12. M. S. Pleshko, O. V. Pashkova, A. A. Nasonov, Gornyi Zhurnal, 3 (2015)

13. M. S. Pleshko, Y. V. Vcherashnyaya, A. A. Nasonov, Gornyi Zhurnal, 10 (2016) 